\title{
A Novel Potentiometric Sensor for Determination of Nitrate ion based on N, N'- Ethylene-bis- (Salicylideneaminato) copper (II)
}

\author{
Mohsin Ali ${ }^{1} \cdot J$ itendra Singh ${ }^{\mathbf{1}^{*}}$ \\ ${ }^{1}$ Department of chemistry, Hemvati Nandan Bahuguna Garhwal University, Srinagar-247174, India \\ *Corresponding author:jeetiitr@gmail.com
}

\section{Received: 7.11.2021; Revised: 17.12.2021; Accepted: 20.12.2021}

(C)Society for Himalayan Action Research and Development

\begin{abstract}
Ionophore $N, N^{\prime}$-Ethylene-bis-(Salicylideneaminato) copper (II) has been synthesized and characterized by IR and 1H NMR spectroscopy. Poly (vinyl chloride) based polymeric films of this ionophore along with cation discriminator $(\mathrm{CTAB})$ and different plasticizers (dibutyl phthalate, dioctyl phthalate, 1-chloronapthalene and tri-n-butyl phosphate) were prepared and investigated as Nitrate ion sensors. Among all the different sensors fabricated, the one with membrane composition as I (7 mg): PVC (31 mg): DBP (60 mg): CTAB (2 mg) exhibited best characteristics. This sensor functions admirably over a wide concentration range $1.0 \times 10^{-6}-1.0 \times 10^{-2} \mathrm{M}$ with Nernstian compliance $(59.8 \mathrm{mV}$ per decade of concentration) between $\mathrm{pH}$ range 2.5-9.2 with a rapid response time of $13 \mathrm{~s}$. The sensor showed a lower detection limit $1.58 \times 10^{-6} \mathrm{M}$. The selectivity coefficient values as determined by the fixed interfering method (FIM) show that the Nitrate ion has excellent selectivity over several anions. The sensor shows satisfactory time span of 2 months with great reproducibility while used continuously daily for 4 hrs. The sensor has been successfully utilized in the determination of nitrate ion concentration in different water samples.
\end{abstract}

Keywords: Potentiometry; nitrate ion; PVC membrane; $N, N$-Ethylene-bis-(Salicylideneaminato) copper (II) ion-selective electrode.

\section{Introduction}

The fabrication of anionic sensors based on polymeric membranes with analytical relevant selectivity stays a difficult task. Indeed, the lipophilic ionophores necessary for the creation of such sensors with significant anion selectivity over others are scarce (Swann et. al. 1975, Bruning-Fann et. al. 1993). The formation of anion sensors and chemosensory has been an essential sub-area within the study of anion chemistry in past few years due to their participation in a range of environmental and biological processes (Gupta et. al. 2008, Singh

et. al. 2007, Jain et. al. 2006, Jain et. al. 2006, Gupta et. al. 2005, Jain et. al. 2005, Prasad et. al. 2004, Gupta et. al. 1999, Jain et. al. 1995). Making potentiometric sensors for anions, be that as it may, remains a challenge due to low charge radii proportion, $\mathrm{pH}$ affectability, and strong solvation energy shown by anions (Beer et. al. 2001, Dietrich et. al. 1993). The identification of nitrate anion is critical because of its presence in the environment, food, industry and human body. The chemical change or biodegradation of nitrate into nitrite, which is 
an indicator of faucal contamination of natural water, is an essential element of nitrate chemistry.Nitrite generates methemoglobinemia, which is detrimental to human health (Eaton et. al. 1995), as a result of its interaction with blood pigment. The standard WHO nitrates/L limit for drinking water is $50 \mathrm{mg} / \mathrm{L}$. Because of its toxicity, nitrate in drinking water is a serious health problem, especially for young children. In humans, the average daily consumption of nitrate/nitrite is $95 \mathrm{mg}$ (Radojevic et. al. 1999). To quantify the measure of nitrate in examples acquired like normal and waste waters, food, modern material, tobacco, and mechanical releases, numerous techniques have been utilized (Davis et. al. 2000, Williams et. al. 1984, Kazemzadeh et. al. 2001, Oms et. al. 1995, Taniai et. al. 2000, Odake et. al. 2001, Aslan-Yilmaz et. al. 2001, Prez-Olmos et. al. 2001). Some depend on ion exchangers with Hofmeister-type selectivity (Heinzmann et. al. 1994, Zhen et. al. 1992), while electrodes based on other ionophores with nitrate ion selectivity have also been developed in recent years (Seung

\section{Experimental}

Reagents: All analytical grade reagent, tri-nbutyl phosphate (TBP) dioctylphathalate (DOP), dibutyl phthalate (DBP), chloronapthalene $(\mathrm{CN})$ and high molecular weight PVC (Polyvinyl chloride) were procured from E. Merck (Mumbai, MH, India). Salicylaldehyde, ethylenediamine, and cetyl trimethylammonium bromide $(\mathrm{CTAB})$ and metal salts were acquired et. al. 2002, Andredakis et. al. 2001, Beltran et. al. 2002, Martijn et. al. 1999, Asghari et. al. 2003, Ardakani et. al. 2004). Literature reports that extensive study has been focused on the development of anions-specific receptors. Metal complexes are now being utilized as anion receptors due to their flexibility which enables them for the modification of the cavity size as well as the creation of strong coordinate connections. Keeping this concept in mind, we developed a new metal complex based on Schiff base $N, N$ '- Ethylene-bis-(Salicylideneaminato) copper (II). This ISE method demonstrated anion receptivity in general and nitrate ion receptivity in particular, with which it had the most affinity. As a result, freshly manufactured receptor is likely to be used as a possible material for constructing polymeric membranes with a specific potential response to the nitrate ion. Therefore, we have constructed and tested PVC-based membranes of $N, N^{\prime}$-Ethylene-bis(Salicylideneaminato) copper (II) as nitrate ion selective sensors.

from from HI Media (Mumbai, India). Tetrahydrofuran (THF), hydrochloric acid, and $\mathrm{NaOH}$ were purchased from (Ranbaxy, India) (Mumbai MH, India). Metal salts were used to produce stock solutions $(0.1 \mathrm{M})$ in double distilled water these solutions were then used to make several diluted solutions whenever required.

Apparatus: At $25 \pm 1^{\circ} \mathrm{C}$, all potentiometric 
measurements were performed with an ESICO INTERNATIONAL Digital potentiometer Model-118 using the proposed sensors in combination with a dual junction $\mathrm{Ag} / \mathrm{AgCl}$ reference electrode. The $\mathrm{pH}$ was measured using a digital pH meter [ESICO INTERNATIONAL Digital pH meter Model-101].

\section{Preparation of ligand N, N'-bis (salicylidene) ethylenediamine (S)}

$50 \mathrm{~mL}$ ethanolic solution of Ethylenediamine $0.67 \mathrm{~g}(5 \mathrm{mmol})$ was added to $20 \mathrm{~mL}$ ethanolic solution of salicylaldehyde $1.22 \mathrm{~g}(10 \mathrm{mmol})$ slowly with constant stirring and the reaction mixture was then refluxed for 5 hours. TLC was used to keep track of the reaction's development. After cooling, the yellowish precipitate was obtained as product which was collected after filtration. The precipitates were rinsed in cold ethanol and dried in desiccator to avoid any moister in the product. Re-crystallization from ethanol was used to purify the product. The melting point was noted as $126.8^{\circ} \mathrm{C}$ and the yield was approximate $82.7 \%$.

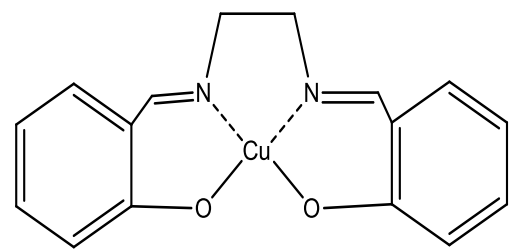

Fig1.N, N'-Ethylene bis (Salicylideneaminato) copper

\section{Fabrication of PVC membranes}

Craggs (Craggs et. al. 1975) suggested constructing PVC membrane electrodes. Ionophore $(\mathrm{Cu}-\mathrm{S})$, cationic excluder (CTAB)

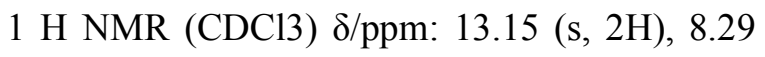
(s, 2H), 7.44 - $7.18(\mathrm{~m}, 4 \mathrm{H}) 6.79-6.89(\mathrm{~m}, 4 \mathrm{H})$, 3.79 (s, 4H). 13C NMR (CDCl3) $\delta / p p m: ~ 165.29$, 161.85, 131.34, 130.35, 116.42, 119.49, 117.81, 58.73 .

\section{Synthesis of prepared metal complexes}

$0.237 \mathrm{~g}$ (1 mmol) copper sulphate was dissolved in $20 \mathrm{~mL}$ double distilled water and it was then mixed to $20 \mathrm{~mL}$ methanolic solution containing $0.268 \mathrm{~g} \quad\left(\begin{array}{ll}1 & \mathrm{mmol}\end{array}\right)$ of $\mathrm{N}, \quad \mathrm{N}-$ bis(salicylidene)ethylenediamine (S). The contents were stirred for 3 hours at room temperature. The resulted precipitate of copper (II) complex was filtered, washed with cold water and dried in vacuum. The dark green product was obtained with a good yield of

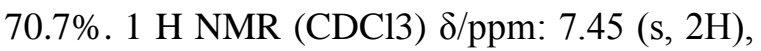
7.39 - $7.19(\mathrm{~m}, 4 \mathrm{H}) 7.10(\mathrm{t}, 2 \mathrm{H}) 6.61(\mathrm{t}, 2 \mathrm{H})$,

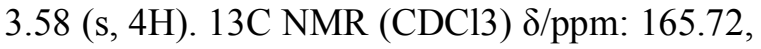
$160.89,132.12$, 131.14, 122.90, 118.85, 114.14, 76.39, 76.29, 76.01, 76.72, 59.4. IR (KBr, $\mathrm{cm}^{-}$ $\left.{ }^{1}\right): 1633(\mathrm{Cu}-\mathrm{N}=\mathrm{C}-), 420(\mathrm{Cu}-\mathrm{N}), 480(\mathrm{Cu}-\mathrm{O})$. 
mm thick was precisely cut from the glass plate and adhered to one corner of Pyrex" glass tube. The membrane distribution and kind of plasticizer utilized are known to have a significant impact on the sensitivity, linearity, and selectivity of a specific ionophore (Bakker et. al. 1997). The ratio of membrane components, contact time, and equilibrating solution concentration were ultimately adjusted after much study. Membranes that create consistent and reproducible potentials have been explored. Blank membranes that don't have ionophore were also made and examined. Ion activity was calculated using a modified version of the Debye-Huckel equation whenever required (Ammann et. al. 1983).

$$
\beta_{I L_{n}}=\left(L_{T}-\frac{n R_{T}}{Z_{I}}\right)^{-n} \exp \left(\frac{E_{M} z_{I} F}{R T}\right)
$$

In order to get complex formation constants, this technique ignores ion pairing. Table 4 shows not really set in stone arrangement constants for the explored different complexes exhibit that the nitrate ion. Accordingly, when contrasted with different ion, it shows complex formation constants properties with ionophore. Table 1 shows that nitrate ion has the highest formation constant for nitrate ion derivation ion contrasted with different ion. Consequently, with ionophore, it exhibits substantial anion-binding properties. when contrasted with another ion.

\section{Potentiometric response}

The potentiometric reaction of a plasticized PVC membrane ion dependent on an ionophore to

\section{Result and discussion}

\section{Calculation of the formation constant}

The stability constants for ionophore complex were dictated by sandwich membrane strategy using the going with condition. Two membrane pieces are interwoven, with only one passing on the ionophore, to make an obsession hypnotized sandwich membrane, which is used to work out the course of action reliable. The membrane capabilities of this transitory state, which changes over into the verified restricting steady of the ion ionophore complex (Qin et. al. 2000), reveals the atom movement degree at the two interfaces. different anions was tried in a pilot explore. Within the sight of the proposed transporter, the upgraded film showed Nernstian reaction and brilliant selectivity for the nitrate anion all through a wide scope of anions. Figure 2 shows the potentiometric reaction bends for an assortment of metal particles utilizing an ionophore under comparative conditions. With the exception of the nitrate ion, $\log \left[\mathrm{NO}_{3}{ }^{-}\right]$ graphs deviate significantly from the anticipated Nernstian slope of $59.8 \mathrm{mV} /$ decade for anions that are univalent or divalent and have extremely narrow direct focus ranges. 
Table 1. Formation constants of ionophore in portioned sandwich-PVC film with various anions

$\begin{array}{cc}\text { Anions } & \text { Formation constant }\left(\log \boldsymbol{\beta}_{\mathbf{I L n}}\right) \\ \mathrm{NO}_{3}{ }^{-} & 6.5 \\ \mathrm{HCO}_{3}{ }^{-} & 3.2 \\ \mathrm{Cl}^{-} & 3.5 \\ \mathrm{SO}_{4}{ }^{2-} & 2.4 \\ \mathrm{NO}_{2}{ }^{-} & 2.5 \\ \mathrm{CO}_{3}^{2-} & 3.6 \\ \mathrm{Br}^{-} & 2.3 \\ \mathrm{CH}_{3} \mathrm{COO}^{-} & 3.0 \\ \mathrm{SCN}^{-} & 3.5 \\ \mathrm{CN}^{-} & 2.2 \\ \mathrm{BrO}_{3}^{-} & 2.3 \\ \mathrm{ClO}_{4}^{-} & 3.7 \\ \mathrm{HPO}_{4}{ }^{-} & 2.5 \\ \mathrm{I}^{-} & 2.4\end{array}$

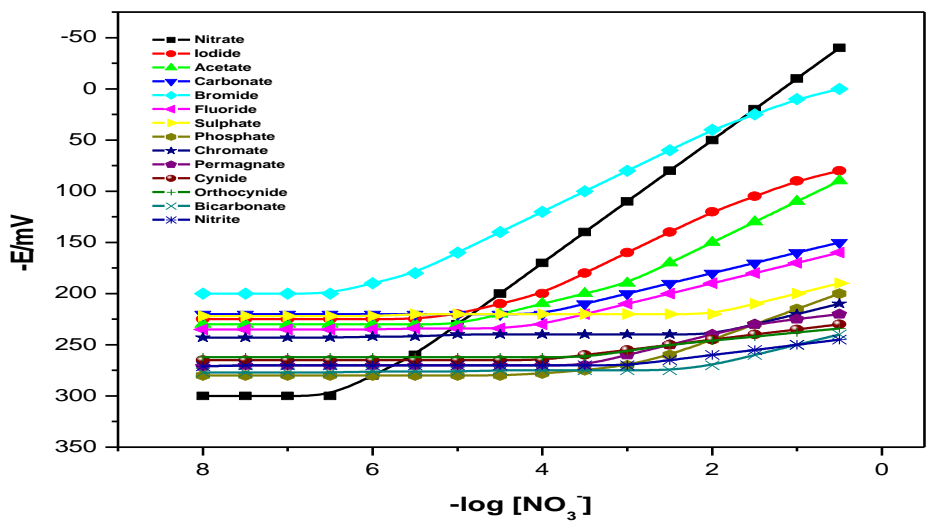

Fig-2 For various anions, the potential response of anion-selective membrane sensor.

The influence of membrane composition on the nitrate sensor's potential response

According to the research, the $\mathrm{N}, \mathrm{N}-$ Ethylene bis (Salicylideneaminato) copper (I) receptor has a high partiality for the nitrate particle in contrast with different ion, and thusly might be utilized as a specific ionophore for potentiometric estimation. The type of the solvent mediator and additive employed and the membrane composition, have a major impact on the sensitivity and performance of an ionophore.
To improve the potentiometric performance of nitrate-selective electrodes, depending on the ionophore, various PVC membrane $\mathrm{N}, \mathrm{N}-$ Ethylene bis (Salicylideneaminato) copper (I) were created and scrutinized. The impact of plasticizer type and fixation on the attributes of a nitrate ion specific anion was researched utilizing 4 plasticizers with various extremity, including DBP, CN, DOP, TBP, and WP (Fig. 3 Table 2). The membrane appears to have generated the maximum level of sensitivity 
without the plasticizer. Better reaction properties, like Nernstian reaction and further developed selectivity, were found with an ideal CTAB level of $2 \mathrm{mg}$ in layer. Table 2 shows the excellent results obtained while optimizing the membrane composition. Several membranes were made and tested with varied compositions, and the best findings on membrane composition optimization are shown in Table 2.

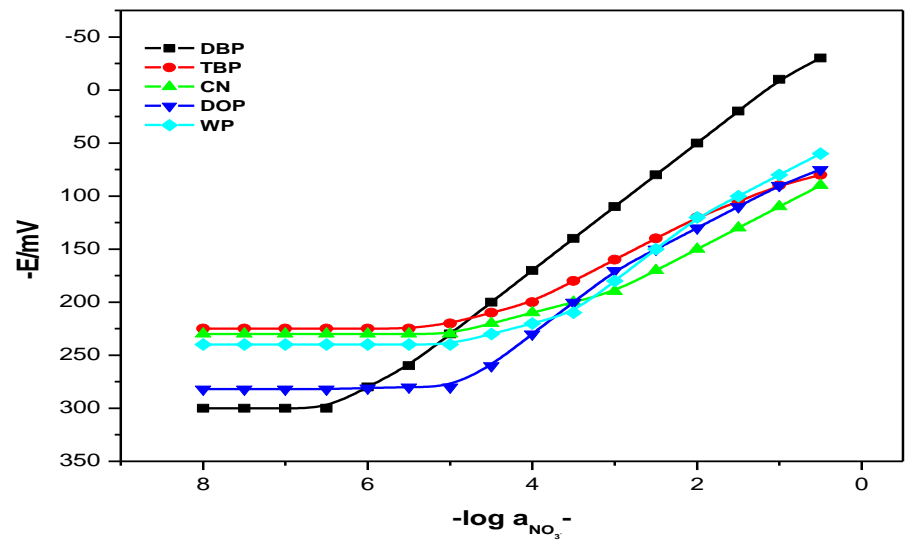

Fig. 3. Various of membrane potential with activity of Nitrate ions.

\section{Sensor performance characteristics}

The potentiometric implementation capabilities of a nitrate particle sensor with different plasticizers based on $\mathrm{N}, \mathrm{N}$ - Ethylene bis (Salicylideneaminato) copper (I) dumbfounding as electroactive material.; 7:31:60:2 mg (I: PVC: DBP: CTAB) in PVC lattice, were tested in the fixation range of $1.0 \times 10^{-6}-1.0 \times 10^{-1} \mathrm{M}$ with Nernstian The results in Table 2 show that sensor no.9 with DBP plasticizer performed wonderfully with a response season of $13 \mathrm{~s}$.To improve the efficiency of plasticized membranes, solvent mediators are frequently employed. The use of plasticizers increases the workability of the membranes and adds considerably to the betterment in working concentration, according to research. Without reasonable plasticizers, the sensor 9 strength and time span of usability ought to be high lipophilicity, high sub-atomic weight, low fume pressing factor, and high ability to break down the substrate and different added substances in the layer 9. Plasticizers further developed sensor affectability, as layers made with DBP demonstrates a straight and consistent reaction for nitrate with a location limit $1.58 \times 10^{-6} \mathrm{M}$ with Nernstian consistence (59.8 $\mathrm{mV}$ each decade). 


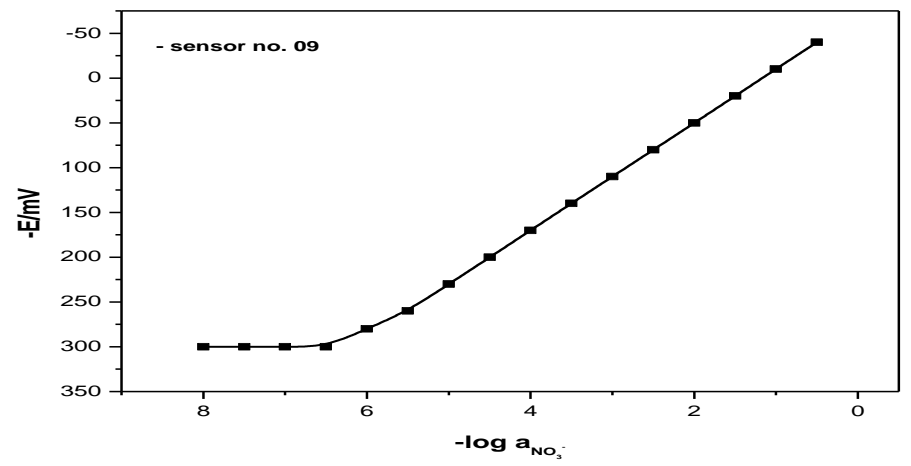

Fig. 4. Calibration plot of fluoride-selective sensors based on ionophores

The polarity of DBP (6.4), which might be determined from the association of accused types of a continuum of a certain constant of hydrophobic, is responsible for DBP's greatest performance among other plasticizers. It was also looked into the concentration. Membrane electrodes no. 9 with 60 wt.\% DBP have better characteristics (slope and detection limit) than membrane electrodes of all other electrodes. As a result, a membrane composition containing $60 \%$ DBP was picked for further testing.

Table 2 shows the composition and response characteristics of the $\mathrm{NO}_{3}{ }^{-}$detecting membrane sensor made of PVC.

\begin{tabular}{|c|c|c|c|c|c|c|c|c|c|c|}
\hline \multirow[t]{2}{*}{$\begin{array}{l}\text { Membr } \\
\text { ane No. }\end{array}$} & \multicolumn{7}{|c|}{$\begin{array}{c}\% \text { Composition (w/w) of various components in } \\
\text { membrane }\end{array}$} & \multirow[t]{2}{*}{$\begin{array}{l}\text { Linear range } \\
\text { (M) }\end{array}$} & \multirow{2}{*}{$\begin{array}{c}\text { Slope } \\
\text { (mV/deca } \\
\text { de of } \\
\text { activity) }\end{array}$} & \multirow[t]{2}{*}{$\begin{array}{l}\text { Respon } \\
\text { se time } \\
\text { (s) }\end{array}$} \\
\hline & $\begin{array}{c}\text { Ionoph } \\
\text { ore }\end{array}$ & $\begin{array}{c}\mathrm{PV} \\
\mathrm{C}\end{array}$ & $\begin{array}{c}\text { CAT } \\
\text { B }\end{array}$ & $\begin{array}{c}\mathrm{DB} \\
\mathrm{P}\end{array}$ & $\mathrm{CN}$ & TBP & DOP & & & \\
\hline 1 & 0 & 33 & 3 & 64 & - & - & - & N.M. & N.M. & N.M. \\
\hline 2 & 6 & 32 & 0 & 62 & - & - & - & $\begin{array}{c}7.4 \times 10^{-5} \text { to } \\
1.0 \times 10^{-2}\end{array}$ & 52.2 & 24 \\
\hline 3 & 6 & 91 & 3 & - & - & - & - & $\begin{array}{c}6.2 \times 10^{-4} \\
\text { to } 1.0 \times 10^{-2}\end{array}$ & 46.5 & 46 \\
\hline 4 & 6 & 31 & 3 & - & - & 60 & - & $\begin{array}{c}7.6 \times 10^{-5} \\
\text { to } 1.0 \times 10^{-2}\end{array}$ & 64.9 & 35 \\
\hline 5 & 6 & 31 & 3 & - & - & - & 60 & $\begin{array}{c}5.7 \times 10^{-5} \\
\text { to } 1.0 \times 10^{-2}\end{array}$ & 62.5 & 56 \\
\hline 6 & 6 & 31 & 3 & - & 60 & - & - & $\begin{array}{c}1.3 \times 10^{-5} \\
\text { to } 1.0 \times 10^{-2}\end{array}$ & 61.3 & 46 \\
\hline 7 & 6 & 32 & 3 & 60 & - & - & - & $\begin{array}{l}7.8 \times 10^{-6} \text { to } \\
1.0 \times 10^{-2}\end{array}$ & 60.4 & 23 \\
\hline 8 & 5 & 32 & 2 & 61 & - & - & - & $\begin{array}{r}3.7 \times 10^{-6} \\
\text { to } 1.0 \times 10^{-2}\end{array}$ & 58.8 & 33 \\
\hline 9 & 7 & 31 & 2 & 60 & - & - & - & $\begin{array}{l}1.0 \times 10^{-6} \text { to } \\
1.0 \times 10^{-1}\end{array}$ & 59.8 & 13 \\
\hline 10 & 8 & 31 & 2 & 59 & - & - & - & $5.0 \times 10^{-6}$ to & 57.9 & 39 \\
\hline
\end{tabular}




\section{$1.0 \times 10^{-2}$}

\section{Potentiometric selectivity}

Selectivity is a key feature of a sensor that determines how well it can estimate analyte ions in the presence of other ions and how useful it is in real-world measurements. Using the fixed interference approach, the selectivity coefficients of the sensor towards various anionic species $\left(\mathrm{A}^{\mathrm{n}-}\right)$ were investigated in this study (MPM)(Umezawa et. al. 1995, Gadzekpo et. al. 1984).

$$
k_{N O_{3-B}^{-}}^{p_{0} t}=\frac{a_{A}^{\prime}-a_{A}}{a_{B}}
$$

According to the IUPAC guideline for calculating selectivity coefficients, (MPM) is the most widely used process. The selectivity coefficients in the (MPM) were calculated using potential measurements on a solution with a fixed concentration of interfering ion $\left(1.0 \times 10^{-1}\right)$ and variable amounts of nitrate ions. When the selectivity coefficient is equal to 1.0 , the response to both main ions is equal to the response to the interfering ion. The selectivity coefficients found by both techniques are considerably less than 1.0, suggesting that the current sensors are significantly selective to the nitrate ion over all interfering ions, as shown in Table 3. The selectivity of the sensor no. 9 (in light of $\mathrm{Cu}-\mathrm{S}$ ) was observed to be better than the other two sensors.

Table-3: The fixed Interference technique was used to calculate selectivity coefficients for a nitrateselective membrane electrode for various interfering ions. (FIM).

Interfering ions
$\mathrm{HPO}_{4}^{2-}$
$\mathrm{HCO}_{3}^{-}$
Iodide
$\mathrm{CO}_{3}^{2-}$
$\mathrm{SO}_{4}^{2}$
$\mathrm{Br}^{-}$
$\mathrm{SCN}^{-}$
$\mathrm{Br}^{-}$
$\mathrm{CH}_{3} \mathrm{COO}^{-}$
$\mathrm{F}^{-}$
$\mathrm{CN}^{-}$
$\mathrm{BrO}_{3}^{-}$
$\mathrm{ClO}_{4}^{-}$
$\mathrm{Cl}^{-}$

Most interfering ions had low selectivity coefficients $\left(10^{-2}, 10^{-3}\right)$, indicating little or minimal interference in the electrode assembly's

$-\log k_{10_{28}^{-0}}^{(n 0.09)} \mathrm{MPM}$
-2.07
-4.34
-2.64
-3.77
-3.16
-2.53
-2.41
-2.39
-3.84
-1.37
-1.90
-1.80
-4.44
-3.10

functioning in table 3, the suggested sensor's selectivity coefficients are contrasted to selectivity coefficients of earlier published PVC- 
permeable nitrate selective electrodes based on various carriers, as well as their other performance features. As can be observed, the suggested electrode has values that are equal in some situations but superior in the majority.

\section{Effect of pH}

The impact of observing arrangement $\mathrm{pH}$ on the membrane electrode potentiometric reaction was researched at $1 \times 10^{-4}$ and $1 \times 10^{-3} \mathrm{M} \mathrm{NO}_{3}$ fixation. Adding a few drops of feeble sulphuric corrosive and $\mathrm{NaOH}$ arrangements altered the $\mathrm{pH}$ according on the scenario. The observations for the ionophores $\mathrm{Cu}-\mathrm{S}$ are presented in Fig. 5, which show that the sensors have a higher responsiveness and linearity at lower $\mathrm{pH}$ levels. The electrode's potentiometric response characteristics degraded somewhat in alkaline solutions owing to central metal coordinated by hydroxide. The ionophore $\mathrm{Cu}-\mathrm{S}$ (sensor no. 9) has a $\mathrm{pH}$ range of 2.5 to 9 .

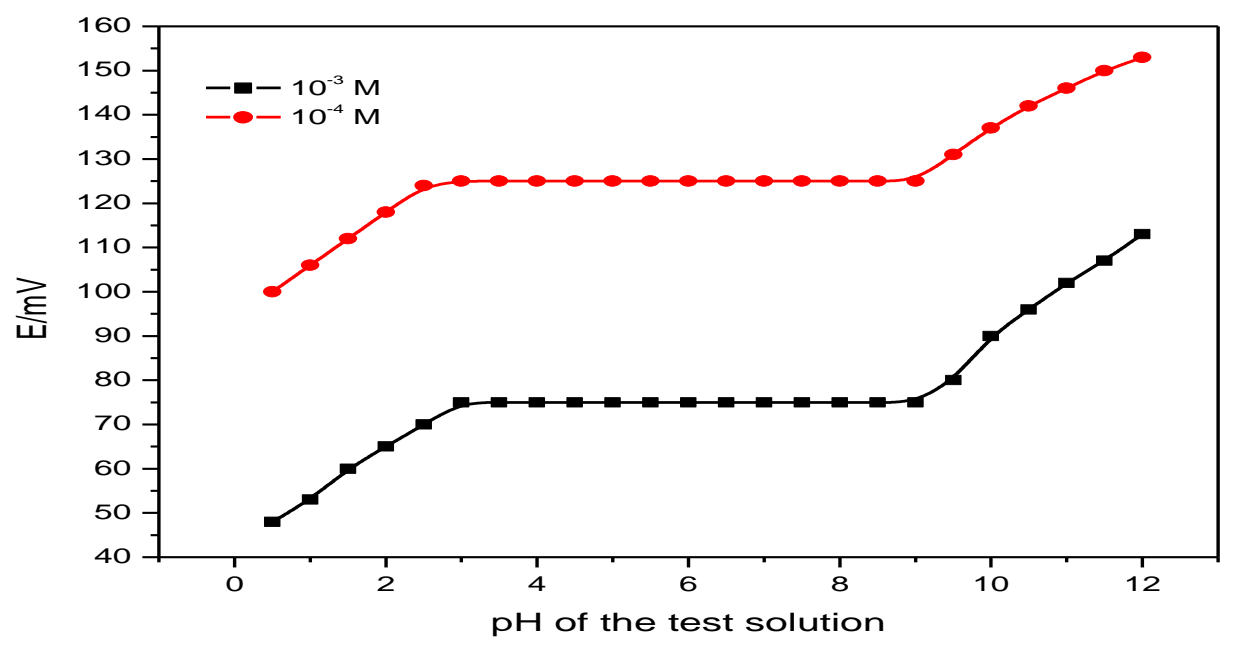

Fig. 5. Effect pf pH on potential response of the fluoride ion-selective sensor.

\section{Dynamic nitrate EMF response of ISE}

In our study, in order to assessing what measure of time of nitrate selective sensor, it needed to show up at $93 \%$ of its equilibrium potential in the wake of being introduced to a $1.0 \times 10^{-3} \mathrm{M}$. It was discovered that the true response time was 13 seconds. By reducing the $\mathrm{NO}_{3}$-sensor in a series of nitrate ion configurations with 10 overlap fastening adjustments, the possible reversibility necessary for the sensor to get a potential within $1 \mathrm{mv}$ of the latest concord esteems was examined. This dynamic reaction is seen in figure 6 as EMF against time. For roughly 3 minutes, the potential remains steady. At the point when potential was recorded from low to high fixations or the other way around, the membrane detecting ion stayed unaltered. 
Table - 4: Based on the ionophore, the lifetime behavior of a nitrate ion-selective electrode (I)

$\begin{array}{cc}\text { Time (days) } & \text { Slope }(\mathbf{m V} / \text { decade) } \\ 1 & 59.8 \pm 0.3 \\ 10 & 59.8 \pm 0.3 \\ 20 & 59.8 \pm 0.3 \\ 30 & 58.8 \pm 0.5 \\ 40 & 58.1 \pm 0.5 \\ 50 & 57.4 \pm 0.8\end{array}$

Detection Limit
$1.58 \times 10^{-6} \pm 0.06$
$1.58 \times 10^{-6} \pm 0.06$
$1.58 \times 10^{-6} \pm 0.06$
$2.70 \times 10^{-6} \pm 0.08$
$3.80 \times 10^{-5} \pm 0.09$
$4.22 \times 10^{-5} \pm 0.07$

Over the course of 45 days, the membranes were was furthermore surveyed in generally nonutilized without causing any notable changes in potentials. Membranes were kept in a freezer if a change in potential was seen. $0.1 \mathrm{M} \mathrm{NO}_{3}^{-}$ solution when not in use. liquid media utilizing methanol-water, ethanolwater, and acetonitrile-water stirs up to $20 \%$ (v/v) non-liquid substance Table 5 Over this, the potential demonstrations erratically.

\section{Effect of non-aqueous content}

Since the model may contain non-aqueous substance, the proposed sensor's presentation

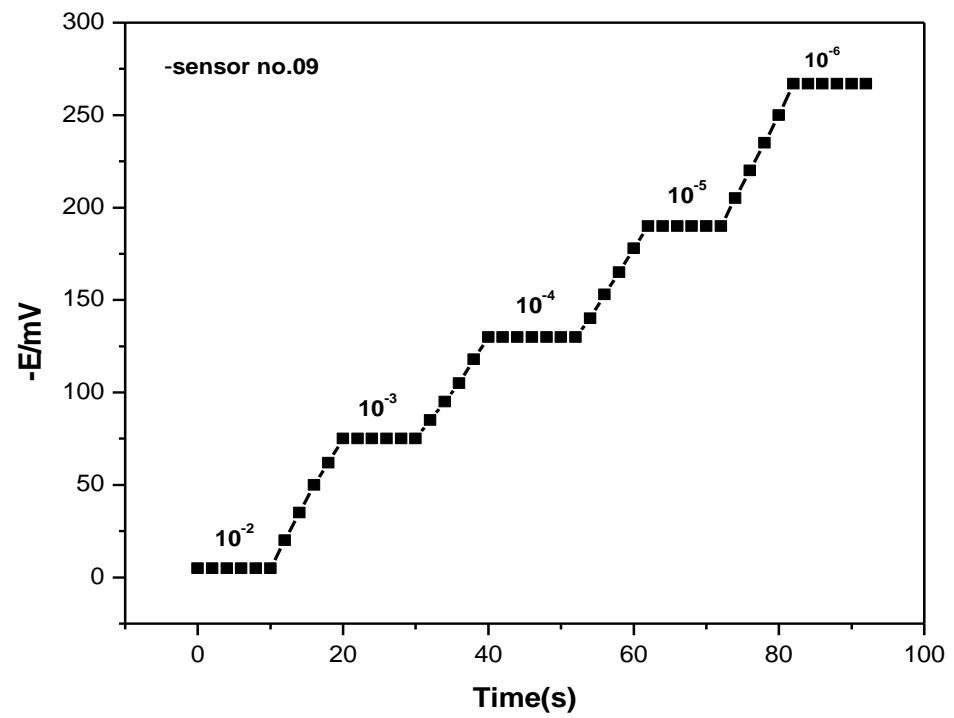

Fig. 6. Study of the best responsive PVC membrane sensor no. 9 in terms of dynamic response time. 
Table- 5 Sensor no. 2's performance in partly non-aqueous medium

$\begin{array}{lcc}\text { Non-aqueous content }(\% \mathbf{v} / \mathbf{v}) & \begin{array}{c}\text { Working concentration } \\ \text { range }(\mathbf{M})\end{array} & \begin{array}{c}\text { Slope }(\mathbf{m v} \text { decade } \\ 1.0 \times 10^{-6}-1.0 \times 10^{-1}\end{array} \\ 0 & 1.0 \times 10^{-6}-1.0 \times 10^{-1} & -59.8 \\ \text { Methanol } & 1.0 \times 10^{-6}-1.0 \times 10^{-1} & -59.8 \\ 10 & 1.8 \times 10^{-6}-1.0 \times 10^{-1} & -59.8 \\ 20 & 2.6 \times 10^{-6}-1.0 \times 10^{-2} & -58.5 \\ 25 & & -58.4 \\ 30 & 1.0 \times 10^{-6}-1.0 \times 10^{-1} & \\ \text { Ethanol } & 1.0 \times 10^{-6}-1.0 \times 10^{-1} & -59.8 \\ 10 & 2.5 \times 10^{-4}-1.0 \times 10^{-2} & -59.8 \\ 20 & 5.2 \times 10^{-6}-1.0 \times 10^{-2} & -59.1 \\ 25 & & -58.5 \\ 30 & 1.0 \times 10^{-6}-1.0 \times 10^{-1} & -59.8 \\ \text { Acetonitrile } & 1.0 \times 10^{-6}-1.0 \times 10^{-1} & -59.8 \\ 10 & 8.5 \times 10^{-5}-1.0 \times 10^{-2} & -59.1 \\ 20 & 2.6 \times 10^{-6}-1.0 \times 10^{-2} & -58.2 \\ 25 & \end{array}$

\section{Analytical Applications}

The improved nitrate-selective electrode was used to identify nitrate in actual samples with great success. Under laboratory circumstances, the electrode performs effectively in pure liquids as well as synthetic mixes. An attempt was performed to detect nitrate in an industrial waste water sample to test the applicability of the suggested electrodes to actual samples. The relevance of nitrate measurement in the water sector is growing as more and more water sources get contaminated with it.

Table-6: Determination of nitrate in different samples $(n=10)$

\begin{tabular}{ccc}
\hline Sample $(\mathbf{p p m})$ & $\begin{array}{c}\text { Spectrophotometric method } \\
(\mathbf{p p m})\end{array}$ & ISE $(\mathbf{p p m})$ \\
\hline Waste water & $18.75 \pm 0.70$ & $18.40 \pm 0.84$ \\
River water & $14.38 \pm 0.32$ & $14.38 \pm 0.32$ \\
Tab water & $11.10 \pm 0.21$ & $11.20 \pm 0.31$
\end{tabular}

Horticultural manures and the oxidation of smelling salts in sewage treatment plants are two significant wellsprings of nitrate, while a couple of systems eliminate nitrate from the water. The spectrophotometric approach was used as a reference technique to quantify the amounts of nitrate in the resultant solutions. The recommended electrode was utilized to analyses a sample $(n=10)$ and the results demonstrate a strong correlation between the 
spectrophotometer's variable values and the proposed electrode (Table 6). Consequently, it is feasible to have faith in electrode performance.

\section{Comparison with other reported sensors}

The comparison of the developed N, N Ethylene bis (Salicylideneaminato) copper (I) complexes selective sensor with the previously reported nitrate sensor and electrode are given in table 7. The developed sensor operates in a wide $\mathrm{pH}$ range than other sensors and has a faster response time.

\section{Table 7. Comparison of the performance of the proposed bromide selective electrode with the} reported electrode

\begin{tabular}{|c|c|c|c|c|}
\hline Ref. & Slope $(\mathrm{mV})$ & Linear range (M) & $\begin{array}{c}\text { Detection limit } \\
(\mathrm{M})\end{array}$ & pH range \\
\hline Asghari et. al. 2003 & -59.6 & $10^{-6}-10^{-1}$ & $2.5 \times 10^{-6}$ & $4.0-12$ \\
\hline Ardakani et. al. 2004 & $-58.5 \pm 1.0$ & $10^{-6}-1.0$ & $1.0 \times 10^{-6}$ & $2.0-9.5$ \\
\hline Lee et. al. 2004 & $-57.8 \pm 1.0$ & $10^{-5}-10^{-1}$ & $5.0 \times 10^{-6}$ & $2.2-9.4$ \\
\hline Ardakani et. al. 2004 & -57.4 & $10^{-5}-10^{-1}$ & $\log \left[\mathrm{NO}_{3}^{-}\right]=-5.72$ & $3.0-9.0$ \\
\hline Gupta et. al. 2011 & $57.0 \pm 0.2$ & $10^{-6}-10^{-1}$ & $3.9 \times 10^{-5}$ & $2.8-9.6$ \\
\hline This work & 59.8 & $10^{-6}-10^{-1}$ & $1.58 \times 10^{-6}$ & $2.5-9.2$ \\
\hline
\end{tabular}

\section{Conclusions}

The results indicate that the N, N-Ethylene bis (Salicylideneaminato) copper (I) may be used as a selective ionophore for nitrate ion measurement using ion-sensors. In contrast to numerous commercial and previously published electrodes, the electrode is more selective towards nitrate. Calibration curve were linear in the $1.0 \times 10^{-1}$ to $1.0 \times 10^{-6}$. The nitrate-selective sensor has a detection limit of $1.58 \times 10^{-6} \mathrm{M}$. and electrode has a $\mathrm{pH}$ range of 2.5 to 9.2 , making it suitable for measurements in a variety of samples as well as in alkaline circumstances. The electrodes have excellent response properties (sensitivity, stability, life duration, and response time).

\section{References}

Amman D, Morf W E, Anker P, Meier P C,
Pretsch E, Simon W (1983). Neutral carrier-based ion-selective electrodes. Ionselective electrode reviews, 5, 3-92.

Andredakis GE, Moschow AE, Matthaiou K, Froudakis G.E., Chaniotakis N.A., (2001) Anion recognition through amide-based dendritic molecule: a poly (vinyl chloride) based sensor for nitrate ion. Anal. Chim. Acta 439: 273-280.

Ardakani M.M., Niasari M.S., Jamshidpoor M. (2004) Selective nitrate poly (vinyl chloride) membrane electrode based on bis(2-hydroxyacetophenone)

ethylenediamine vanadyl (IV). Sens. Actuators B: Chem. 101: 302-309.

Ardakani M M, Dastanpour A, Salavati-Niasari M (2004). A highly selective nitrate electrode based on a tetramethyl cyclotetra- 
decanato-nickel (II) complex. $J$.

Electroanalytical Chemistry, 568, 1-6.

Aslan-Yilmaz N, Kenar A, Atakol O, Kilic EA (2001) Anion recognition through amidebased dendritic molecule: A poly (vinyl chloride) based sensor for nitrate ion. Anal.

Sci. 17: 1269-1275.

Asghari A.R., Amini M.K., Mansour H.R., Niasari M.S. (2003) A tetra-coordinate nickel (II) complex as neutral carrier for nitrate-selective PVC membrane electrode. Talanta 61: 557-563.

Bakker E, Bühlmann P, Pretsch E (1997). Carrier-based ion-selective electrodes and bulk optodes. $1 . \quad$ General characteristics. Chemical Reviews, 97(8), 3083-3132.

Beer PD, Gale PA (2001) Anion Recognition and Sensing: The State of the Art and Future Perspectives. Chem. Int. Ed. 40: 486-516.

Beltran A., Artigas J., Jimenez C., Mas R., Bartroli J., Alonso J. (2002) Development of Durable Nitrate-Selective Membranes for All-Solid-State ISE and ISFET Sensors Based on Photocurable Compositions. Electroanalysis 14: 213-220.

Bruning-Fann C.S., Kaneene J.B. (1993) The effects of nitrite and $\mathrm{N}$-nitroso compounds on human health: a review. Vet. Hum. Toxicol 35: 521-538.

Craggs A, Keil L, Moody G J, Thomas J D R (1975). An evaluation of solvent mediators for ion-selective electrode membranes based on calcium bis (dialkylphosphate) sensors trapped in poly (vinyl chloride) matrices. Talanta, 22(10-11), 907-910.

Davis J., Moorcroft M.J., Wilkins S.J., Compton R.G., Cardosi M.F. (2000) Electrochemical Detection of Nitrate at a Copper Modified Electrode Under the Influence of Ultrasound. Electroanalysis 12: 1363-1371. Dietrich B. (1993) Pure Appl. Chem. 651: 457471.

Eaton A.D., Clesceri L.S., Greenberg A.E., (1995) Standard Methods for the Examination of Water and Wastewater. American Public Health Association, Washington.

Gadzekpo V P Y, Christian G D (1984). Determination of selectivity coefficients of ion-selective electrodes by a matchedpotential method. Analytica ChimicaActa, 164, 279-2.

Gupta V.K., Goyal R.N., Sharma R.A. (2008) Anion recognition using newly synthesized hydrogen bonding disubstituted phenylhydrazone-based receptors: Poly (vinyl chloride)-based sensor for acetate. Talanta 76: 859-864.

Gupta V.K., Ludwig R., Agarwal S. (2005) Anion recognition through modified calixarenes: a highly selective sensor for monohydrogen phosphate. Anal. Chim. Acta 538: 213-218.

Gupta V.K., Jain A.K., Singh L.P., Khurana U., 
Kumar P. (1999) Molybdate sensor based on5,10,15,20-etraphenylporphyrinatocobalt complex in a PVC matrix. Anal. Chim. Acta 379: 201-208.

GuptaV K, Singh L P, Chandra S, Kumar S, Singh, R., \& Sethi, B. (2011). Anion recognition through amide-based dendritic molecule: a poly (vinyl chloride) based sensor for nitrate ion. Talanta, 85(2), 970974.

Heinzmann G., Czolk R., Ache H.J. (1994) Investigation of the stability of an optochemical nitrate sensor. Sens. Actuators B: Chem. 47: 18-19.

Jain A.K., Gupta V.K., Raisoni J.R. (2006) Anion recognition using newly synthesized hydrogen bonding diamide receptors: PVC based sensors for carbonate. Electrochim. Acta 52: 951-957.

Jain A.K., Gupta V.K., Raisoni J.R. (2006) A newly synthesized macrocyclic dithiooxamide receptor for phosphate sensing. Talanta 69: 1007-1012.

Jain A.K., Gupta V.K., Singh L.P., Srivastava P., Raisoni J.R. (2005) Anion recognition through novel C-thiophenecalix [4] resorcinarene: PVC based sensor for chromate ions. Talanta 65: 716-721.

Jain A.K., Gupta V.K. Singh L.P. (1995) Anion recognition through amide-based dendritic molecule: A poly (vinyl chloride) based sensor for nitrate ion. Anal. Proc. (RSC) 32: 263-265.
Kazemzadeh A., Ensafi A.A., (2001) Simultaneous determination of nitrite and nitrate in various samples using flowinjection spectrophotometric detection. J. Microchem. 69: 159-166.

Lee, H. K., Song, K., Seo, H. R., \& Jeon, S. (2004). Nitrate-selective electrodes based on meso-tetrakis [(2-arylphenylurea)phenyl] porphyrins as neutral lipophilic ionophores. Talanta, 62(2), 293-297.

Martijn A.G.M., Reinhoudt D.N. (1999) Potentiometric Anion Selective Sensors. Electroanalysis 11: 1035-1048.

Myers, M., Khir, F. L. M., Podolska, A., Umana-Membreno, G. A., Nener, B., Baker, M., \& Parish, G. (2013). Nitrate ion detection using $\mathrm{AlGaN} / \mathrm{GaN}$ heterostructure-based devices without a reference electrode. Sensors and Actuators B: Chemical, 181, 301-305.

Odake T., Tabuchi M., Sato T., Susaki H., Korenaga T. (2001). Fluorescent Derivatization of Nitrite Ions with 2,3Diaminonaphthalene Utilizing a $\mathrm{pH}$ Gradient in a Y-shaped Microchannel. Anal. Sci. 17: 535-538.

Oms M.T., Cerda A., Cerda V. (1995) Sequential injection analysis of nitrites and nitrates Anal. Chim. Acta 315: 321-330.

Prasad R., Gupta V.K., Kumar A. (2004) Metallo-tetraazaporphyrin based anion sensors: regulation of sensor characteristics through central metal ion coordination. 
Anal. Chim. Acta 508: 61-70.

Prez-Olmos R., Rios A., Fernandez J.R., Lapa

R.A.S., Lima J.L.F.C. (2001) Construction and evaluation of ion selective electrodes for nitrate with a summing operational amplifier. Application to tobacco analysis. Talanta 53: 741-748.

Qin, Y., Mi, Y., \& Bakker, E. (2000). Determination of complex formation constants of 18 neutral alkali and alkaline earth metal ionophores in poly (vinyl chloride) sensing membranes plasticized with bis (2-ethylhexyl) sebacate and onitrophenyloctylether. Analytica chimica acta, 421(2), 207-220.

Radojevic M., Bashkin V.N. (1999) Practical Environmental Analysis, RSC, UK.

Seung J.C., Satoshi S., Kazunori I., Isao K. (2002) A simple nitrate sensor system using titanium trichloride and an ammonium electrode. Sens. Actuators B: Chem. 85: $120-125$.

Singh A.K., Gupta V.K., Gupta B. (2007) Chromium (III) selective membrane sensors based on Schiff bases as chelating ionophores. Anal. Chim. Acta 585: 171178.

Swann P.F. (1975) The toxicology of nitrate, nitrite and n-nitroso compounds. J. Sci. Food Agric. 26: 1761-1770.

Taniai T., Sakuragawa A., Okutani T. (2000) Anion recognition through amide-based dendritic molecule: A poly (vinyl chloride) based sensor for nitrate ion. Anal. Sci. 16: 275-286.

Umezawa, Y., Umezawa, K., \& Sato, H. (1995). Selectivity coefficients for ion-selective electrodes: recommended methods for reporting KA, Bpot values (Technical Report). Pure and applied chemistry, 67(3), 507-518.

Williams S. (1984) AOAC, Official Methods of Analysis of the Association of Official Analytical Chemists, Washington D.C.

Zhen R.G., Smith S.G., Miller A.J. (1992) A Comparison of Nitrate-selective Microelectrodes made with Different Nitrate Sensors and the Measurement of Intracellular Nitrate Activities in Cells of Excised Barley Roots. J. Exp. Bot.43:131138. 